\title{
EDITORIAL
}

\section{AÑOS UNIDOS A TRAVÉS DEL CONOCIMIENTO}

La Facultad de Estomatología Roberto Beltrán está cumpliendo su 40 Aniversario y profesores, alumnos y personal administrativo que la integran, así como sus egresados deben sentirse orgullosos de su existencia por la labor desarrollada en la formación de cientos de jóvenes odontólogos, especialistas en las diferentes ramas de la odontología, magísteres, doctores y también de técnicos y asistentes dentales. Todos ellos, con seguridad, juegan un papel positivo e importante en el cuidado de la salud bucal y en el ejercicio de una profesión cada vez más orientada a la prevención, a la utilización de tecnología avanzada y con un gran sentido de responsabilidad para asumir el papel que les toca jugar en los ámbitos de la vida económica, social y cultural de nuestro país.

Podemos afirmar que se ha cumplido con los propósitos y la filosofía que los fundadores de esta gran institución establecieron en el año 1969; principios que destacan, entre otros, el impartir educación odontológica del más alto nivel, formar profesionales que entienden y desean contribuir con la solución de los problemas de salud bucal de las poblaciones más necesitadas, dispuestos a seguir estudiando para obtener los conocimientos y las habilidades para brindar a cada uno de sus pacientes el mejor tratamiento.

Debemos reconocer que durante estos 40 años la tarea no ha sido fácil y ha demandado de parte de sus miembros mucho trabajo, esfuerzo, dedicación y compromiso personal para remontar obstáculos y llegar al escenario en que hoy nos encontramos, el de una Institución cada día más fuerte, más visible, más propositiva y con mayor reconocimiento a nivel nacional e internacional.

En este proceso de formación de profesionales verdaderamente universitarios indudablemente no estamos satisfechos y debemos seguir aportando, no podemos dudar, no podemos bajar la guardia y debemos seguir reconociendo que no hay progreso sin conocimiento y no hay conocimiento sin educación y que esta simbiosis educación y conocimiento no es únicamente responsabilidad de las autoridades sino de todos los miembros que integran la Facultad.

A lo largo de sus 40 años de vida académica la Facultad de Estomatología Roberto Beltrán, ha realizado innumerables aportes a nuestro país en el campo de su competencia dentro de los cuales podemos señalar:

- Formación de Odontólogos de alto nivel científico, técnico y de gran sensibilidad social.

- Formación de Asistentes Dentales a nivel universitario.

- Formación de Técnicos Dentales a nivel universitario.

- Creación del primer Programa de Internado Odontológico Hospitalario.

- Creación del primer Programa de Internado Odontológico Rural.

- Creación de las primeras Clínicas Odontológicas Periféricas y Escolares.

- Creación del Sistema de Servicio Estomatológico Docente Asistencial.

- Creación del Programa de Diplomado en Estomatología.

- Creación del primer Programa de Especialización en Estomatología.

- Creación de los programas de Maestría en Estomatología, Maestría en Estomatología con Mención en Especialidad y Doctorado en Estomatología.

La Facultad de Estomatología Roberto Beltrán cuenta con una excelente plana de profesores, la mayoría con títulos de Especialista y grados de Magíster y de Doctor formados en la propia Facultad y en prestigiosas universidades de Estados Unidos y Europa. Para la formación clínica de pre y 
postgrado dispone de dos modernas clínicas dentales, así como laboratorios y otras facilidades que garantizan una enseñanza de primer nivel.

Los avances logrados por la Facultad de Estomatología son el resultado del trabajo del selecto grupo de docentes que la conforman, de la calidad de sus estudiantes y del dedicado trabajo de su personal administrativo.

Estamos seguros que sus miembros seguirán trabajando y aunando voluntades en pro del progreso de su Facultad. Sus esfuerzos y dedicación lograran mantener permanentemente el reconocimiento de Institución con Acreditación Internacional en su carrera de Estomatología que es el reconocimiento a la alta calidad de este programa.

No dudamos que el espíritu de ciencia que reina en las aulas heredianas, servirán también para profundizar en estudiantes y profesores el sentido de responsabilidad social que seguirá poniéndose de manifiesto en cada una de las acciones de servicio que se brinda a las comunidades de nuestro país. Se continuará cultivando en los estudiantes el pensamiento crítico e independiente y la capacidad de aprender durante toda la vida, fomentando la innovación y la diversidad.

En el cuadragésimo aniversario de la Facultad de Estomatología Roberto Beltrán, la Revista Estomatológica Herediana saluda y felicita a todos sus miembros y se compromete a seguir siendo una publicación seria con miras a alcanzar el reconocimiento que le permita figurar en todas las bases de datos de revistas científicamente reconocidas. 